\title{
THEORETICAL INVESTIGATION OF ROTARY DIGGING TOOL PARAMETERS FOR POTATO TUBERS
}

\author{
Volodymyr Bulgakov ${ }^{1}$, Ivan Holovach ${ }^{1}$, Vitaliy Bonchik ${ }^{2}$, Semjons Ivanovs ${ }^{3}$, Volodymyr Volskiy ${ }^{4}$, Juri \\ $\mathrm{Olt}^{5}$ \\ ${ }^{1}$ National University of Life and Environmental Sciences of Ukraine, Ukraine; \\ ${ }^{2}$ State Agrarian and Engineering University in Podillia, Ukraine; \\ ${ }^{3}$ Latvia University of Life Sciences and Technologies, Latvia; \\ ${ }^{4}$ Institute for Agricultural Engineering and Electrification, Ukraine; \\ ${ }^{5}$ Estonian University of Life Sciences, Estonia \\ semjons@apollo.lv
}

\begin{abstract}
The development, design and research of the parameters of new potato harvesters is an important and urgent task in the field of potato production. The aim of this research is to substantiate rational design and kinematic parameters of the lower and the upper blades of the beaters of the vertical rotor of a potato harvester by determining the velocities of collision of the blades with the tuberous layer of their most characteristic points. Theoretical investigations have been carried out, and then, using the calculations on a PC, graphical dependencies of the main parameters of the process under study were constructed. The values of absolute velocities of collision of the lower and upper blades of the vertical rotor beaters, respectively, at the initial and final points with the tuberous layer of the soil, were determined. The values of the absolute velocities of collision of the lower and the upper blades of the vertical rotor blades were determined, respectively, at the initial and final points with the tuberous layer of the soil. Rational kinematic parameters of the lower and the upper blades of the vertical rotor beaters are calculated, respectively, at the initial and the final points, where the greatest destruction of the tuberous layer occurs. For the lower blade of the beater, the absolute collision speed at the angle of rotation $\omega_{n} t=120^{\circ}$ at the starting point is $V_{s p}{ }^{n}=1.69 \mathrm{~m} \cdot \mathrm{s}^{-1}$, at the end point $-V_{s p}{ }^{n}=1.94 \mathrm{~m} \cdot \mathrm{s}^{-1}$. For the upper blade of the beater, the absolute speed of collision at a terming angle $\omega_{b} t=120^{\circ}$ at the starting point is $V_{s p}{ }^{b}=1.63 \mathrm{~m} \cdot \mathrm{s}^{-1}$, at the end point $-V_{s p}{ }^{b}=1.92 \mathrm{~m} \cdot \mathrm{s}^{-1}$. The angular velocity of the rotational motion of the upper and the lower rotor blades was equal to $\omega=10.46 \mathrm{~s}^{-1}$.
\end{abstract}

Keywords: potatoes, digging, rotor, blade, turnability, lumps.

\section{Introduction}

Potatoes are an important food and industrial crop [1;2]. Potato production is an important agricultural sector in many countries, including Ukraine, Poland and the Baltic countries [3; 4].

Harvesting potatoes is one of the most complex and energy-intensive technological operations in their production, the quality of which largely depends on the labour intensity of further processing operations and the duration of storage of the resulting product [5-7]. Unlike many other crops, for harvesting potatoes it is necessary to dig in and raise a layer of soil, significant in volume and mass, and separate the tubers from it with a purity of at least $80 \%$ and a degree of damage of no more than $3 \%$ [8]. One of the main directions how to improve the harvesting quality of potatoes is the operation of cutting out a whole potato bed and its further destruction. During digging the potato bed and transporting it to the separating tools the tuberous layer is subjected to a static and dynamic action of the lump-grinding tools, as a result of which the formed lumps of soil with potato tubers are destroyed. The most widespread use on modern potato harvesters for crushing lumps of a potato bed is the dynamic impact of working tools.

We have developed a new two-row trailed potato harvester, which implements the above principle of the tuber harvesting, i.e. unloading of two adjacent potato beds, their destruction with the help of vertical rotor beater blades. In this case, the beater consists of the lower and the upper blades, mounted together with a drive reducer on a vertical rotor, located in the inter-row spacing. The driven planetary gearbox ensures opposite directions of the rotary movements of the lower and the upper blades with the same angular velocities. A structural and technological diagram of the potato harvester is shown in Fig 1. The technological process of digging potatoes out of the soil takes place in this way. Rollers 1 copy two adjacent potato rows and deform them under the impact of their weight. Further, the vertical rotor 2 , which actually performs the functions of a digging tool, moving in the inter-row spacing, due to the upper and lower blades of the beater, destroys the soil layer of the inter-row spacing, as well as the layer containing the potato tubers from both rows, and efficiently destroys it. Besides, the two lower blades of the beater form a conical shape, i.e. they are fixed on the drive shaft obliquely; and the surface, formed 
by the two upper blades has the shape of a cylinder. The working width of the vertical rotor 2 is such that the upper blades with their ends periodically capture the tuber-bearing parts of the rows, tear them off and drop them in the centre of the entire working width. The lower two blades of the beater, forming a conical shape, capture the deep-lying potato tubers, lift them up and actually feed them into the zone of action of the upper blades of the beater. Opposite directions of the rotator movements of the lower and the upper blades provide an additional effect of dispersing the tuberous layers into separate components, which guarantees separation of the potato tubers from the surrounding soil. Further, the spherical guide discs 3 mechanically shift the tuberous layer to a fixed (small in size) width. After that, the share 4 lifts the doubled roller to the bar elevator 5 , mounted on a frame with support wheels 6 . The shaker 7 , installed on the elevator 5 , intensifies the process of separating the soil impurities through its rods and is used, if necessary, in the case of a significant amount of free soil and soil adhered to the potato tubers themselves. Finally, the potato tubers, completely cleaned of the soil impurities and plant residues, fall onto the harvested area of the field. In the case of using this digging-separating system as an integral unit of a self-propelled potato harvester, the cleaned potato tubers can be fed either into the bunker or into the body of a nearby vehicle.

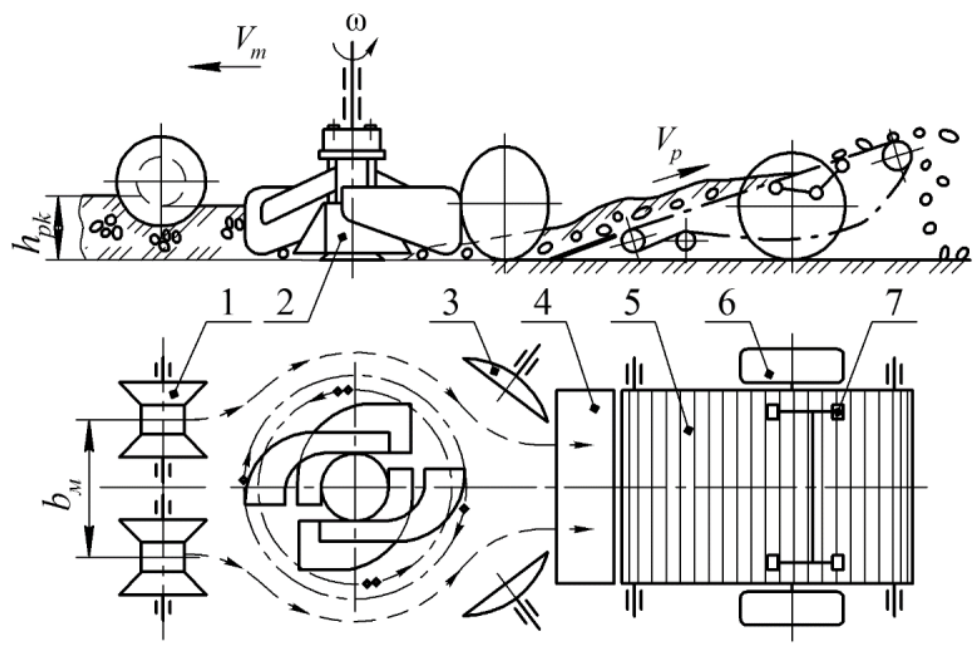

Fig. 1. Structural and technological diagram of a double-row trailed potato harvester:

1 - copying rollers; 2 - vertical rotor with the lower and upper blades; 3 - spherical guide discs;

4 - share for raising the doubled roller; 5 - rod elevator; 6 - support wheel; 7 - shaker

In addition, the design of this potato harvester provides for regulation of the distance $b_{M}$ - the distance between the potato rows and $h_{p k}$ - the depth of travel in the soil of the vertical rotor 2 with the lower and the upper blades. The forward speed $V_{m}$ of this potato harvester, the angular speed of the vertical rotor 2, as well as the linear speed $V_{m}$ of the rod elevator 5 can be set in a wide range of their values, due to specific conditions for harvesting potatoes.

It follows from the analysis of the strength of the layers of a potato row for medium loamy soils that the most intensive destruction of lumps must be carried out in the lower layers of the bed. To reduce the percentage of damage to the tubers, the impact of the working tools upon the tuberous layer should not exceed the limit of the impact forces [3; 4]. Fundamental foundations for the study of the regularities of the process of harvesting potatoes, the destruction of the lumps, depending on the mechanical factors, are set forth in the works $[5 ; 7 ; 9]$. According to numerous investigations, the destruction of lumps of the medium and heavy loams under static compression requires a force of not more than $150 \ldots 160 \mathrm{~N}$, and for the tubers the allowed destructive force is $250 \ldots 300 \mathrm{~N}$. Nevertheless, when the soil moisture is less than 10\%, the mechanical strength of the lump can reach $500 \ldots 600 \mathrm{~N}$ for some types of soil. By many investigations and tests of potato harvesters it has been established that complete destruction of a lump on heavy loam without significant damage to the tubers is possible at a moisture content of more than $16 \%$. But in this case the maximum strength of the lump should not exceed $100 \ldots 150 \mathrm{~N}$. At a moisture content above $25 \%$, the soil becomes plastic and viscous, as a result of which the lump flattens during compression, i.e. deforms without collapsing, and the working gaps of the separating tools stick up, and separation of the soil impurities is not ensured [11]. In the process of improving the experimental machine, a need arises for an analytical study of the regularities of destruction of a potato row at the 
beginning of the technological process, i.e. the impact on it of a vertical rotor with the lower and upper blades, and further collection of the destroyed mass with a narrow ploughshare for transporting it onto the rod conveyor $[8 ; 10 ; 12]$. The purpose of the research is to substantiate rational design and kinematic parameters of the lower and upper blades of the beaters of the vertical rotor of a potato harvester by determining the speed of collision of the blades with the tuberous layer of their most characteristic points.

\section{Materials and methods}

The investigation was conducted using the provisions of analytical geometry and differential calculus, the theory of agricultural machines, methods of compiling programs for numerical calculations on a PC [13-15]. A characteristic feature of the operation of the vertical rotor blades is that they are installed on the upper and the lower beaters, which rotate on the same shaft due to the planetary gear in opposite directions with a gear ratio of 2.39 , and also taking part in two movements simultaneously: the forward movement - together with the potato harvester, and the rotary movement around the rotor axis. In addition, the forward speed $V_{m}$ for both blades will be the same, but the peripheral speeds $V_{k}$ will be different. During rotation the blades should have a variable effect upon the tuberous layer depending on the depth of digging. For this it is necessary that the peripheral speed of the ends of the lower blades of the beater, in contrast to the upper ones, is higher. In order to ensure smooth running and to reduce the degree of damage to the potato tubers, the working surface of the blade of the lower beater should have a conical shape, and the surface of the blade of the upper beater should be in the shape of a cylinder. To calculate the speeds of collision of the lower and the upper rotor blades with the tuberous layer, it is necessary to determine the trajectories of the movement, the magnitude and the direction of the speeds of the most characteristic points of these blades. Taking into account the geometric shape of the working surfaces and the direction of rotation of the blades, calculations must be made for the extreme points of the outer contours of these blades.

Let us consider the movement of the lower blade of the beater and construct a diagram of the movement of the lower blade of the beater, highlighting and examining the movements of its characteristic points. So, we select the first characteristic point $A$, located on the outer surface of this blade, which, in the normal direction, is the first to start a contact with the tuberous layer. The second characteristic point $B$ is also located on the outer surface of the blade, and it is placed at its end. Besides, the lower blade of the beater performs a rotational movement, directed counter clockwise, with the given angular velocity $\omega_{n}$ in a horizontal plane, also moving together with the potato harvester at a constant forward velocity $V_{m}$. Since the working surface of the lower blade is inclined to the horizon at a set angle, it will be limited by the outer and the inner contours, the movement of which must be considered. Let in the initial position of the rotor (centre $O$ of its drive shaft) the characteristic points of the blades $A$ and $B$ located away from the axis of the drive shaft, i.e. from point $O$, at distances (radii) $-r$ and $R$, respectively. For a certain period of time $t$, the centre of the rotor drive shaft (point $O$ ), moving forward together with the potato harvester, arrived in a position $O_{1}$ at a distance $V_{m} t$. The characteristic points of the blade $A$ and $B$, making a rotational movement with an angular velocity $\omega_{n}$, in the indicated direction moved along their trajectories and took new positions $A 1$ and $B 1$, respectively. At the same time, their radii relative to point $O_{1}$ became equal to $r_{1}$ and $R_{1}$, respectively. For the new position the radii of the key points $A_{1}$ and $B_{1}$ will be turned by the same angles $\omega_{n} t$ (Fig. 3). Let us show a coordinate system on the diagram. To do this, we use a system of rectangular Cartesian coordinates $x O y$, placing it in a horizontal plane, and the origin placing at point $O$. Besides, we will direct the $O x$ axis along the forward movement of the potato harvester, and the $O y$ axis will be located perpendicular to it. Let us compose an equation of the trajectory of the movement for two points $A_{1}$ and $B_{1}$ of the outer contour of the beater

Using the designations, adopted in the diagram, shown in Fig. 3, we first write down the coordinates for point $A_{1}$ in the adopted coordinate system $x O y$, which will represent the equation of the trajectory of this point in a horizontal plane and will have the following form:

$$
\left.\begin{array}{l}
x_{A_{1}}=V_{m} \cdot t-r_{1} \cdot \sin \left(\omega_{n} t-\frac{\pi}{2}\right), \\
y_{A_{1}}=-r_{1} \cdot \cos \left(\omega_{n} t-\frac{\pi}{2}\right),
\end{array}\right\}
$$


or in a final form:

$$
\left.\begin{array}{l}
x_{A_{1}}=V_{m} \cdot t+r_{1} \cdot \cos \omega_{n} t, \\
y_{A_{1}}=-r_{1} \cdot \sin \omega_{n} t .
\end{array}\right\}
$$

In a similar way, we write down the coordinates for point $B_{1}$, which will also be represented by an equation of the trajectory of this point in a horizontal plane:

$$
\left.\begin{array}{l}
x_{B_{1}}=V_{m} \cdot t+R_{1} \cdot \cos \left(\omega_{n} t-\frac{\pi}{2}\right), \\
y_{B_{1}}=-R_{1} \cdot \sin \left(\omega_{n} t-\frac{\pi}{2}\right),
\end{array}\right\}
$$

or in a final form:

$$
\left.\begin{array}{l}
x_{B_{1}}=V_{m} \cdot t+R_{1} \cdot \sin \omega_{n} t \\
y_{B_{1}}=R_{1} \cdot \cos \omega_{n} t,
\end{array}\right\}
$$

where $V_{m}-$ forward speed of the potato harvester, $\mathrm{m} \cdot \mathrm{s}^{-1}$;

$t$ - arbitrary turning time of the lower beater, $\mathrm{s} ; r_{1}$,

$R_{1}$ - radii for the extreme points of the lower blades, respectively, m;

$\omega_{n}$ - angular velocity of the blades of the lower beater, $\mathrm{rad} \cdot \mathrm{s}^{-1}$;

$\omega_{n} t$-turning angle of the blade of the lower beater at an arbitrary moment of time $t$.

Next, we define the projections of the velocities of the lower blade of the beater on the corresponding axes of coordinates $x$ and $y$ as the first derivatives of the coordinates of these points with respect to time $t$. For point $A_{1}$ the first time derivatives $t$ of expressions (2) will give the sought velocity projections:

$$
\begin{gathered}
V_{x A_{1}}=\frac{d x_{A_{1}}}{d t}=\frac{d\left(V_{m} \cdot t+r_{1} \cdot \cos \omega_{n} t\right)}{d t}=V_{m}-r_{1} \cdot \omega_{n} \cdot \sin \omega_{n} t, \\
V_{y A_{1}}=\frac{d y_{A_{1}}}{d t}=\frac{d\left(-r_{1} \cdot \sin \omega_{n} t\right)}{d t}=-r_{1} \cdot \omega_{n} \cdot \cos \omega_{n} t .
\end{gathered}
$$

In a similar way we find the projections of the velocities for point $B_{1}$ on the $x$ and $y$ axes, differentiating expressions (4) with respect to time $t$. We have:

$$
\begin{gathered}
V_{x B_{1}}=\frac{d x_{B_{1}}}{d t}=\frac{d\left(V_{m} \cdot t+R_{1} \cdot \sin \omega_{n} t\right)}{d t}=V_{m}+R_{1} \cdot \omega_{n} \cdot \cos \omega_{n} t, \\
V_{y B_{1}}=\frac{d y_{B_{1}}}{d t}=\frac{d\left(R_{1} \cdot \cos \omega_{n} t\right)}{d t}=-R_{1} \cdot \omega_{n} \cdot \sin \omega_{n} t .
\end{gathered}
$$

\section{Results and discussion}

Using the obtained expressions (5)-(8), we successively find expressions for the absolute velocities of points $A_{1}$ and $B_{1}$, considering them to be the absolute velocities of collision of these points with the tuberous layer. Thus, the absolute speed of collision of the lower blade of the beater with the tuberous layer, respectively, at the beginning $V_{s p A 1}$ and at the end $V_{s p B 1}$ of the outer contour of the lower blade is determined according to the following dependencies:

$$
\begin{gathered}
V_{s p A_{1}}=\sqrt{\left(V_{m}-r_{1} \cdot \omega_{n} \cdot \sin \omega_{n} t\right)^{2}+\left(-r_{1} \cdot \omega_{n} \cdot \cos \omega_{n} t\right)^{2}}, \\
V_{s p B_{1}}=\sqrt{\left(V_{m}+R_{1} \cdot \omega_{n} \cdot \cos \omega_{n} t\right)^{2}+\left(-R_{1} \cdot \omega_{n} \cdot \sin \omega_{n} t\right)^{2}} .
\end{gathered}
$$


Let us further transform expressions (9) and (10). Since $V_{O A 1}=r_{1} \cdot \omega_{n}, V_{O B 1}=R_{1} \cdot \omega$, are the linear velocities of points A1 and B1, respectively, expressions (9) and (10) can be written in the following form:

$$
\begin{aligned}
& V_{s p A_{1}}=\sqrt{\left(V_{m}-V_{O A_{1}} \cdot \sin \omega_{n} t\right)^{2}+\left(-V_{O A_{1}} \cdot \cos \omega_{n} t\right)^{2}}, \\
& V_{s p B_{1}}=\sqrt{\left(V_{m}+V_{O B_{1}} \cdot \cos \omega_{n} t\right)^{2}+\left(-V_{O B_{1}} \cdot \sin \omega_{n} t\right)^{2}} .
\end{aligned}
$$

After the necessary transformations have been completed, we obtain:

$$
\begin{aligned}
& V_{s p A_{1}}=\sqrt{V_{m}^{2}+V_{O A_{1}}^{2}-2 V_{m} \cdot V_{O A_{1}} \cdot \sin \omega_{n} t}, \\
& V_{s p B_{1}}=\sqrt{V_{m}^{2}+V_{O B_{1}}^{2}+2 V_{m} \cdot V_{O B_{1}} \cdot \cos \omega_{n} t},
\end{aligned}
$$

or in a final form:

$$
\begin{gathered}
V_{s p A_{1}}=V_{O A_{1}} \cdot \sqrt{1+\frac{V_{m}^{2}}{V_{O A_{1}}^{2}}-2 \frac{V_{m}}{V_{O A_{1}}} \cdot \sin \omega_{n} t}, \\
V_{s p B_{1}}=V_{O B_{1}} \cdot \sqrt{1+\frac{V_{m}^{2}}{V_{O B_{1}}^{2}}+2 \frac{V_{m}}{V_{O B_{1}}} \cdot \cos \omega_{n} t} .
\end{gathered}
$$

The obtained expressions (15) and (16) make it possible to analytically determine the linear velocities of the collision of the characteristic points of the lower blade of the beater with the soil layer, containing the potato tubers. Further we will separately consider the trajectory of the upper blade of the beater, which carries out a rotational movement in the opposite direction, i.e. rotates in a clockwise direction with a constant angular velocity $\omega_{b}$ in a horizontal plane, also moving uniformly forward together with the potato harvester at a given speed $V_{m}$.

In order to study the movement of the characteristic points of this blade, we will also draw up a diagram. Since the working surface of the upper blade has the shape of a cylinder, it can be limited only by the outer contour, by composing the equation of the trajectory of motion for the two extreme points $A$ and $B$. In this case point $A$ is the point of the first contact of the blade with the tuberous layer, and point $B$ is at the end of the blade. As in the previous case, the initial position of the rotor is indicated by point $O$, located in the centre of its drive shaft. The indicated characteristic points of blades $A$ and $B$ are also located away from the axis of the drive shaft at distances (radii) - $r$ and $R$, respectively. In a certain period of time $t$, the centre of the rotor drive shaft (point $O$ ), moving forward together with the potato harvester, moved to position $O_{1}$ at a distance $V_{\mathrm{m}} t$. The characteristic points of blades $A$ and $B$, making a rotational movement with an angular velocity $\omega_{b}$ in the clockwise direction, moved along their trajectories of movement and took new positions $A_{1}$ and $B_{1}$, respectively. At the same time, their radii relative to point $O_{1}$ became equal to $r_{1}$ and $R_{1}$, respectively. For the new position the radii of the characteristic points $A_{1}$ and $B_{1}$ of the upper blade will also be rotated by the same angles $\omega_{b} t$. As in the previous case, the diagram shows a similar coordinate system $x O y$ (Fig. 4).

Using the scheme, shown in Fig. 4, we also write down at the beginning the coordinates for point $A_{1}$ in the adopted coordinate system, which will represent the equation of the trajectory of this point and will have the following form:

$$
\left.\begin{array}{l}
x_{A_{1}}=V_{m} \cdot t+r_{1} \cdot \cos \omega_{b} t \\
y_{A_{1}}=r_{1} \cdot \sin \omega_{b} t .
\end{array}\right\}
$$

Similarly, we will write down the coordinates for point $B_{1}$ of the upper blade of the beater, which will also represent the equation of the trajectory of this point: 


$$
\left.\begin{array}{l}
x_{B_{1}}=V_{m} \cdot t+R_{1} \cdot \sin \omega_{b} t, \\
y_{B_{1}}=-R_{1} \cdot \cos \omega_{b} t,
\end{array}\right\}
$$

where $\omega_{b}-$ angular velocity of the upper blade of the beater, $\mathrm{rad}^{-1} \mathrm{~s}^{-1}$.

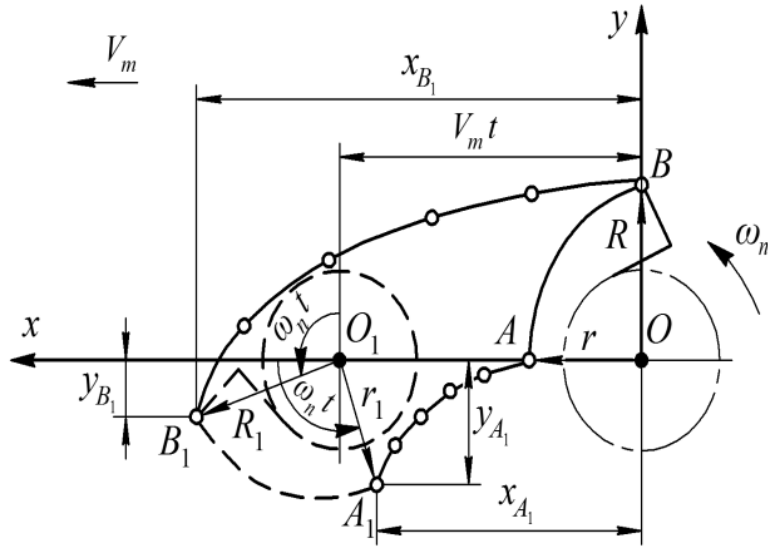

Fig. 3. Diagram for determination of the trajectory of the movement of two extreme points of the outer contour of the lower blade of the beater

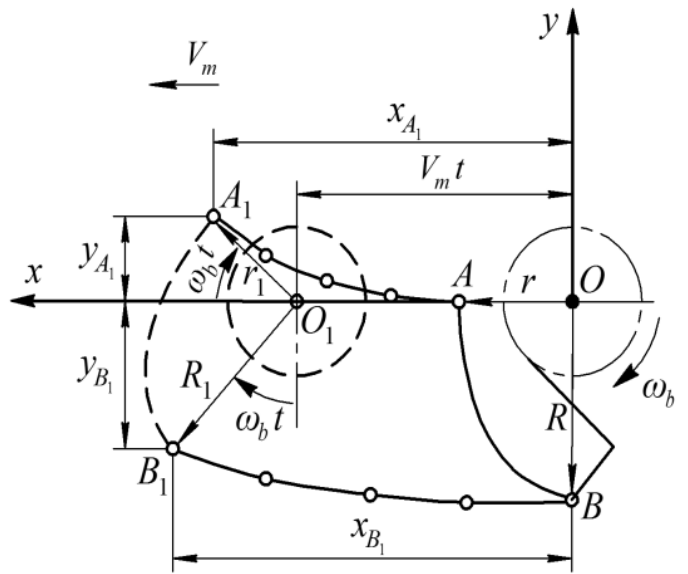

Fig. 4. Scheme for determining the trajectory of the movement of two extreme points of the upper blade of the beater

We will define the projections of the velocities of the upper blade of the beater on the corresponding coordinate axes as the first derivatives of the coordinates of these points on the $x$ and $y$ coordinate axes with respect to time. For point $A_{1}$, the first time derivatives $t$ of expressions (17) will give the sought velocity projections:

$$
\begin{gathered}
V_{x A_{1}}=\frac{d x_{A_{1}}}{d t}=\frac{d\left(V_{m} \cdot t+r_{1} \cdot \cos \omega_{b} t\right)}{d t}=V_{m}-r_{1} \cdot \omega_{b} \cdot \sin \omega_{b} t, \\
V_{y A_{1}}=\frac{d y_{A_{1}}}{d t}=\frac{d\left(-r_{1} \cdot \sin \omega_{b} t\right)}{d t}=-r_{1} \cdot \omega_{b} \cdot \cos \omega_{b} t
\end{gathered}
$$

In a similar way we find the projection of the velocities for point $B_{1}$ on the $x$ and $y$ axes. Taking the derivatives from expressions (18), we have:

$$
\begin{gathered}
V_{x B_{1}}=\frac{d x_{B_{1}}}{d t}=\frac{d\left(V_{m} \cdot t+R_{1} \cdot \sin \omega_{n} t\right)}{d t}=V_{m}+R_{1} \cdot \omega_{n} \cdot \cos \omega_{n} t, \\
V_{y B_{1}}=\frac{d y_{B_{1}}}{d t}=\frac{d\left(R_{1} \cdot \cos \omega_{n} t\right)}{d t}=-R_{1} \cdot \omega_{n} \cdot \sin \omega_{n} t .
\end{gathered}
$$

The absolute speed of collision of the upper blade of the beater with the tuberous layer at the beginning and at the end of the outer contour of the blade, respectively, is determined by the formulas:

$$
\begin{gathered}
V_{s p A_{1}}=\sqrt{\left(V_{m}-r_{1} \cdot \omega_{b} \cdot \sin \omega_{b} t\right)^{2}+\left(-r_{1} \cdot \omega_{b} \cdot \cos \omega_{b} t\right)^{2}}, \\
V_{s p B_{1}}=\sqrt{\left(V_{m}+R_{1} \cdot \omega_{b} \cdot \cos \omega_{b} t\right)^{2}+\left(-R_{1} \cdot \omega_{b} \cdot \sin \omega_{b} t\right)^{2}} .
\end{gathered}
$$

If we take into account that $V_{O A 1}=r_{1} \cdot \omega_{b}, V_{O B 1}=R_{1} \cdot \omega_{b}$, where $V_{O A 1}, V_{O B 1}$ are the peripheral velocities of points $A_{1}$ and $B_{1}$, respectively, $\mathrm{m} \cdot \mathrm{s}^{-1}$, substitute them into expressions (23) and (24), then we will have: 


$$
\begin{gathered}
V_{s p A_{1}}=\sqrt{\left(V_{m}-V_{O A_{1}} \cdot \sin \omega_{b} t\right)^{2}+\left(-V_{O A_{1}} \cdot \cos \omega_{b} t\right)^{2}}=\sqrt{V_{m}^{2}+V_{O A_{1}}^{2}-2 V_{m} \cdot V_{O A_{1}} \cdot \sin \omega_{b} t}, \\
V_{s p B_{1}}=\sqrt{\left(V_{m}-V_{O B_{1}} \cdot \cos \omega_{n} t\right)^{2}+\left(-V_{O B_{1}} \cdot \sin \omega_{b} t\right)^{2}}=\sqrt{V_{m}^{2}+V_{O B_{1}}^{2}-2 V_{m} \cdot V_{O B_{1}} \cdot \cos \omega_{b} t},
\end{gathered}
$$

or

$$
\begin{gathered}
V_{s p A_{1}}=V_{O A_{1}} \cdot \sqrt{1+\frac{V_{m}^{2}}{V_{O A_{1}}^{2}}-2 \frac{V_{m}}{V_{O A_{1}}} \cdot \sin \omega_{b} t}, \\
V_{s p B_{1}}=V_{O B_{1}} \cdot \sqrt{1+\frac{V_{m}^{2}}{V_{O B_{1}}^{2}}-2 \frac{V_{m}}{V_{O B_{1}}} \cdot \cos \omega_{b} t} .
\end{gathered}
$$

Using the obtained final expressions according to the developed program in the MathCAD environment on a PC, numerical calculations were carried out, as a result of which graphical dependences of the speed of collision of the lower and the upper rotor blades with the tuberous layer were obtained, which are shown in Fig. 5 and Fig. 6. It is evident from the graphs, shown in Fig. 5, that with an increase in the turning angle of the lower blade of the beater $\omega_{n} t$ within the range from 0 to $120^{\circ}$, the absolute speed of collision $V_{s p}{ }^{n}$, respectively, at the beginning and at the end of the outer contour of the blade increases, and at the initial point is $V_{s p}{ }^{n}=1.69 \mathrm{~m} \cdot \mathrm{s}^{-1}$, and at the final point $V_{s p}{ }^{n}=1.94 \mathrm{~m} \cdot \mathrm{s}^{-1}$, at the maximum angular velocity of the rotary motion $\omega_{n}=10.46 \mathrm{~s}^{-1}$. The nature of these dependences is approximately the same also for the other values of the angular velocities $\omega_{n}$ of rotation of the lower blade of the beater.

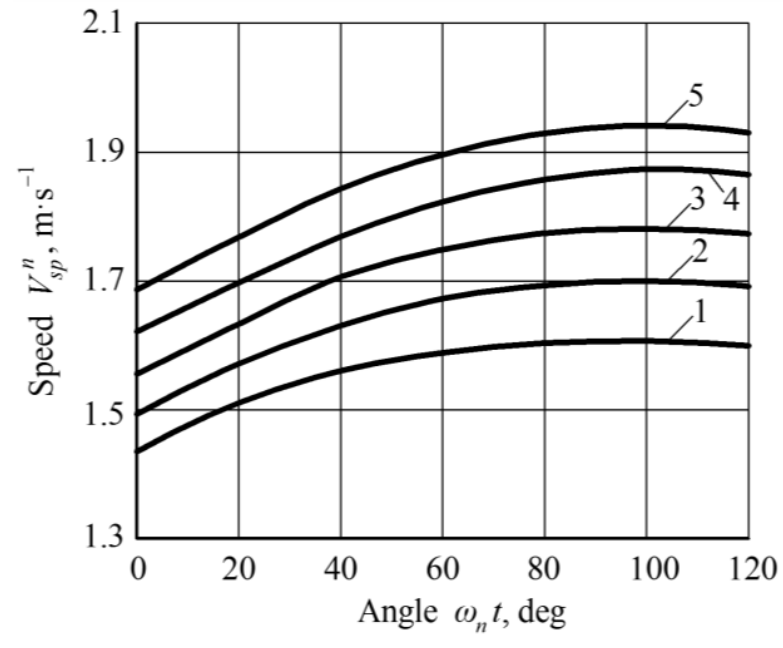

Fig. 5. Dependence of the speed of collision $V_{s p}{ }^{n}$ of the lower beater blades with a tuberous layer upon the angle of rotation $\omega_{n} t$ for various values $\omega_{n}: 1-\omega_{n}=2.09 \mathrm{~s}^{-1}$;

$$
\begin{aligned}
& 2-\omega_{n}=4.18 \mathrm{~s}^{-1} ; 3-\omega_{n}=6.28 \mathrm{~s}^{-1} ; \\
& 4-\omega_{n}=8.09 \mathrm{~s}^{-1} ; 5-\omega_{n}=10.46 \mathrm{~s}^{-1}
\end{aligned}
$$

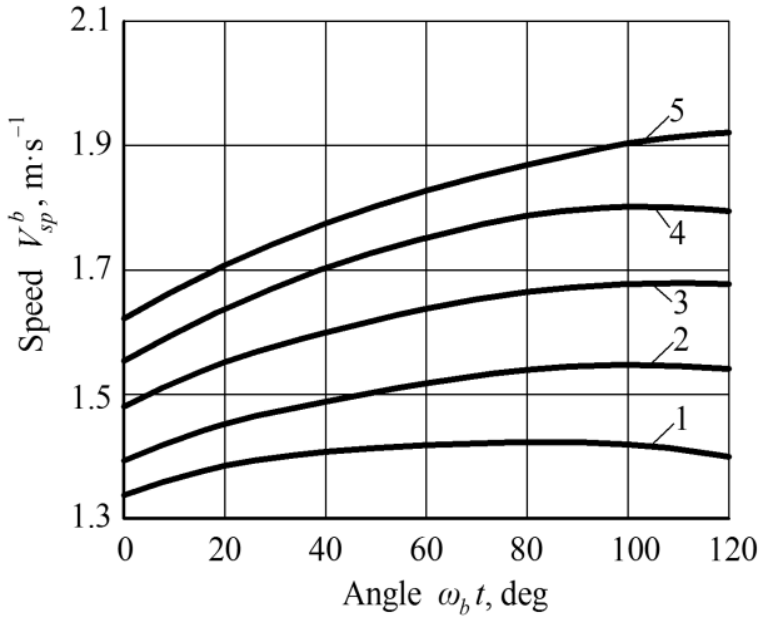

Fig. 6. Dependence of the speed of collision $V_{s p}^{b}$ of the upper blade of the beater with a tuberous layer upon the angle of rotation

$$
\begin{gathered}
\omega_{b} t: 1-\omega_{b}=2.09 \mathrm{~s}^{-1} ; 2-\omega_{b}=4.18 \mathrm{~s}^{-1} ; \\
3-\omega_{b}=6.28 \mathrm{~s}^{-1} ; 4-\omega_{b}=8.09 \mathrm{~s}^{-1} ; 5-\omega_{b} \\
\omega_{b}=10.46 \mathrm{~s}^{-1}
\end{gathered}
$$

The graphs, shown in Fig. 6, also allow us to assert that with an increase in the turning angle of the upper blade of the beater up to $\omega_{b} t=120^{\circ}$ (within the range $0 \ldots 120^{\circ}$ ), the absolute collision velocity $V_{s p}{ }^{b}$, respectively, at the beginning and at the end of the outer contour of the blade increases, and at the initial point it is $V_{s p}{ }^{b}=1.63 \mathrm{~m} \cdot \mathrm{s}^{-1}$, and at the final point $-V_{s p}{ }^{b}=1.92 \mathrm{~m} \cdot \mathrm{s}^{-1}$, with the maximum angular velocity of rotary motion $\omega_{b}=10.46 \mathrm{~s}^{-1}$. The nature of these dependences is also approximately the same for the other values of the angular velocities $\omega_{b}$ of rotation of the upper blade of the beater, as it was for the lower blade of the beater. 


\section{Conclusions}

1. On the basis of the performed theoretical studies graphical dependencies were obtained that allow calculating the rational kinematic parameters of the lower and the upper blades of the beater, that is, the working tools of the vertical rotor of the potato harvester, respectively, at the initial and the final points, where the greatest destruction of the tuberous layer of potatoes occurs.

2. It was established that for the lower blade of the beater the absolute speed of collision of the blade with the tuberous layer at its rotation angle $\omega_{n} t=120^{\circ}$ at the initial point is $V_{s p}{ }^{n}=1.69 \mathrm{~m} \cdot \mathrm{s}^{-1}$, and at the end point $-V_{s p}{ }^{n}=1.94 \mathrm{~m} \cdot \mathrm{s}^{-1}$. For the upper blade of the beater the absolute speed of collision with the potato-bearing layer at the angle of rotation of this blade equal to $\omega_{b} t=120^{\circ}$, at the initial point the collision speed is $V_{s p}{ }^{b}=1.63 \mathrm{~m} \cdot \mathrm{s}^{-1}$, at the end point $-V_{s p}{ }^{b}=1.92 \mathrm{~m} \cdot \mathrm{s}^{-1}$. These values were obtained at the same maximum angular velocity of the rotary movement of the upper and the lower rotor blades, equal to $\omega=10.46 \mathrm{~s}^{-1}$.

\section{References}

[1] Keijbets M.J.H. Potato processing for the consumer: Developments and future challenges. Potato Research, 51 (3-4), 2008, pp. 271-281.

[2] Shpaar D. 2004. Potatoes. Minsk, 465 p.

[3] Sawicka B., Hameed, T. Farmers' knowledge of sustainable potato cultivation techniques in poland . Agron. sci, 74, 2019, pp. 81-98

[4] Bulgakov V., Pascuzzi S., Ivanovs S., Ruzhylo Z., Fedosiy I., Santoro F. A new spiral potato cleaner to enhance the removal of impurities and soil clods in potato harvesting. Sustainability (Switzerland), Vol. 12, Issue 23, 2020, Article number 9788, pp. 1-19.

[5] Петров Г. Машины для уборки картофеля (Potato Harvesting Machines). Moscow: Mashinostroenije, 2004. 320 p. (In Russian).

[6] Scott, G.J. Maps, models, and muddles: World trends and patterns in potatoes revisited. Potato Research, 45 (1), 2002, pp. 45-77

[7] Wei H., Wang D., Lian W., Shao S., Yang X., Huang X. Development Of 4ufg1400 Type Potato Combine Harvester. Transactions O The Chinese Society Of Agricultural Engineering. Vol. 29(1), 2013, pp. 11- 17.

[8] Parlak M., Blanco-Canqui H. Soil losses due to potato harvesting: A case study in western Turkey. Soil Use and Management. Vol. 31 (4), 2015, pp. 525-527

[9] Mitrofanov V. Physico-mechanical properties of potatoes: theory, design and production of agricultural machinery, $1997,511 \mathrm{p}$.

[10] Karwowski T. Teoria i konstrukcia maszyn rolniczych (Theory and design of agricultural machinery). Warsawa: 20116429 p. (In Polish)

[11] Hevko R., Tkachenko I., Synii S., Flonts I. Development of design and investigation of operation processes of small-sclale root crop and potato harvesters. INMATEH - Agricultural Engineering.Vol.49 (2), 2016, pp. 53-60

[12] Ivanovs S., Adamovics A., Rucins A. Investigation of the technological spring harvesting variants of the industrial hemp stalk mass. Agronomy Research. Volume 13, Issue 1, 2015, pp.73-82

[13] Dreizler R.M., Ludde C.S. Theoretical Mechanics, Springer: 2010, 402 p.

[14] Bulgakov V., Aboltins A., Ivanovs S, Holovach I., Nadykto V., Beloev H. A mathematical model of plane-parallel movement of the tractor aggregate modular type. Agriculture, Vol.10 (10), 2020, art.454, pp.1-21. 